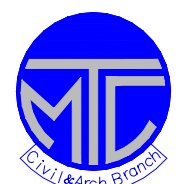

\title{
ICCAE
}

Military Technical College

Kobry Elkobbah, Cairo, Egypt

\author{
6hㅡ International Conference \\ On Civil \& Architecture \\ Engineering
}

\section{COMPUTER MODELLING OF CHANNEL FLOW USNG AN INVERSE METHOD}

\author{
Graham J.M. Copeland 1*, Hossam Mohammed**.
}

\begin{abstract}
:
We may not be able to command the water to stop but we can take steps to predict when and where it will invade and attack our lives, and provide solutions to deal with the problem. The research project reported in this paper is concerned with a study of unsteady free surface water flow, a hydrograph, resulting from a watershed just after the outlet station. The quality of flood predictions by numerical models depends on the accuracy of the inflow hydrograph, other control variables such as bed roughness, infiltration rate, and channel topography. However, none of these are well known, the values of each are uncertain. This research examines what effect these uncertainties have on the flood prediction. That is we find out how the uncertainties in control values propagate through the model. This is achieved by calculating the sensitivities of the flood predictions to changes (uncertainties) in control variables. The adjoint method is used to study the sensitivity of the flow to changes in the boundary and initial conditions. To achieve this aim we constructed a numerical hydraulic model to simulate the flow of water in the main stream based on the shallow water equation (SWE). The sensitivities are determined using the adjoint method which uses a variational technique to find the relationships between changes in channel flow conditions and changes in control variables such as the inflow hydrograph. This could be done at significant computational expense using multiple runs and ensemble techniques however the adjoint method presented here determines these sensitivities analytically in one run of the model.
\end{abstract}

\section{Keywords}

Hydrograph, Watershed, Finite Difference Method, Method Of Characteristics, Shallow Water Equations (SWE), and Adjoint Sensitivity Analysis.

* Head of Civil Engineering Department, Strathclyde University, Scotland, U.K.

**PhD student, Civil Engineering Department, Strathclyde University, Scotland, U.K. 


\section{1 . INTRODUCTION:}

\subsection{Numerical methods and Sensitivity Analysis}

Numerical techniques had been applied recently to hydraulic research and computional fluid dynamics for several purposes such as the prediction of flood wave propagation in rivers (Steinebach 1998), the prediction of circulation in estuaries for hazardous spill response (Cheng et al. 1993), and coastal flow modelling (Copeland 1998). Once the outcome of an environmental hazard such as a flood wave propagation in our case has been predicted, it is important to consider what control actions will mitigate the impact of this hazards. Possible control actions in river flow systems that can be investigated using numerical models include the modification of reservoir release rates, the operation of control structures such as gates, locks, weirs, and the diversion of water into canals and floodplain storage facilities (Sanders et al. 2000). Other 'controls' that act to determine the result of a model forecast, rather than offering an engineering control, are values of the inflow hydrograph and, for example, the values of other control variables such as bed roughness, infiltration rate, and channel topography. In this paper we find out how the uncertainties in these control values propagate through the model and affect flood level forecasts.

There are two main approaches to the determination of the sensitivity of forecasted flood levels to uncertainties in control variables that can be used in any forecast model. The first is to solve the forecasting model repetitively using different parameter selections corresponding to different values of control variables, the outcome associated with each possible control value can be ascertained. This approach is the direct method of determining the sensitivities, the computational cost of this exercise is great, rendering this approach too slow for real-time applications. An adjoint method, on the other hand, allows the change in an outcome resulting from a changes (uncertainties) in several different control variables to be assessed with just one additional simulation regardless of the number of potential controls. The adjoint method represents a procedure whereby the basic problem and its associated adjoint problem are sequentially solved (D.G.Cacuci ,2003). A sensitivity expression, a function of the basic problem and adjoint problem solution, subsequently can be applied to assess the change in outcome resulting from changes in control settings (sensitivities) (Sanders et al. 2000). 
The potential of the variational framework, which has been widely used in ground water hydrology, meteorology, oceanography, surface hydrology, and more recently in land surface hydrology for catchment modeling have been investigated in this paper for hydraulic simulation at stream flow scale. Results at this paper are very encouraging and have demonstrated new ideas for addressing some issues in hydrologic modeling especially stream flow modelling.

In this paper, an adjoint method is presented that can be used for control of shallow-water flow in the main channel of a watershed. The boundary conditions necessary for real-time flood wave control are studied. The method of characteristics (MOC) (M.B. Abbott 1977) had been applied for the adjustment of the shallow-water equations near the boundaries and expressions for adjoint sensitivity for the propagation of a hydrograph along a stream.

Sanders et al. 2000 documented that open boundary conditions at the hydraulic model must achieve dual objectives. First, the boundary conditions must supply to the model information from adjacent water bodies not included in the model. Second, the boundary conditions must allow disturbances generated within the solution domain to propagate without any changes through the computational open boundaries.

In the case of stream flow we studied to achieve these objectives, the upstream driving hydrograph should be propagated through the domain without any disturbance till it reaches the downstream boundary and passes through it without any reflections. No physical mechanism is present in the real world to generate a reflection at computational open boundaries, so none should occur in the model. Otherwise, incorrect values of sensitivity may be computed at the boundary, which can contaminate the information necessary to quantify boundary control. In this paper, we show the characteristic equations for the adjoint problem, which, in combination with the characteristic equations of the basic problem, allows the formulation of a new set of adjoint boundary conditions that provide the correct adjoint senstivities to uncertainties in control variable at the boundaries and elsewhere in the domain.

\subsection{Mechanism of Water Flow:}

A watershed is composed of sub-areas and reaches (major flow paths in the watershed). Each sub-area has a hydrograph generated from the area based on the land and climate characteristics provided. Hydrographs from sub-areas and reaches are combined to 
accumulate flow as water moves from the upland areas down through the watershed reach network. The accumulation of all runoff from the watershed is represented at the watershed Outlet station.
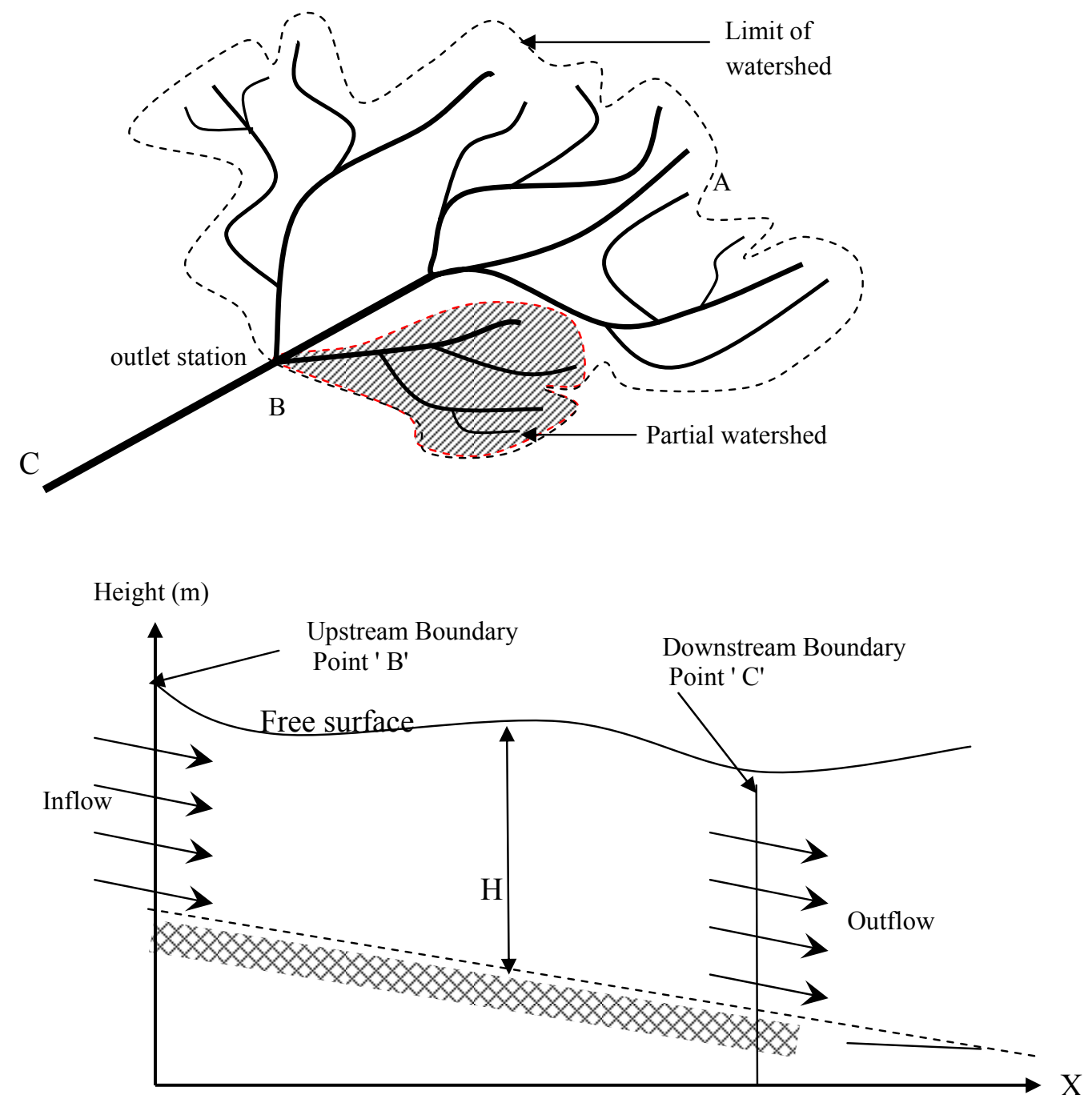

Fig.1. Flow within the Watershed

So the hydrological response of a "watershed" could be divided into two different stages as illustrated in Fig. 1. each of them is completely different in its condition of water flow, behavior, parameters, and methods of study.

The first stage within a natural unit of land which is known as watershed in which water from direct precipitation, snowmelt, and other storage collects in a (usually surface) channel and 
flows downhill along the main stream from point "A" to point "B" which is the out let station as illustrated in Fig. 1.

At the second stage the water flow is considered as channel flow from point " $\mathrm{B}$ " to point " $\mathrm{C}$ " which is completely different in its characteristics, the set of parameters that specifies the particular characteristics of the process, the mathematical relations describing its physical processes, physical meaning, and modeling.

A stream routing component is used to represent flood wave movement in a channel. The input for this component is an upstream hydrograph resulting from individual or combined contributions of sub area runoff, stream flow routings, or diversions. This hydrograph is routed to a downstream point, using the characteristics of the channel. The techniques available to route the runoff hydrograph include the Muskingum method, level-pool routing, and the kinematics wave method (U.S. Army Corps of Engineer, 1988).

\subsection{Flash Floods and River Floods:}

Flash floods are short-term rapid response inundations of small areas such as a town or parts of a city, usually by creeks and other smaller tributaries that flow into larger rivers. Heavy rain can produce flash flooding in a few hours even in places where little rain has fallen for weeks or months. In arid or semiarid regions, flash flooding can send a wall of water that turns a completely dry valley, wadi or canyon into a raging torrent in seconds.

If heavy rainfall occurs repeatedly over a wide area, then river or mainstream flooding becomes more likely, in which the main rivers of a region swell and inundate large areas, sometimes well after rainfall has ended as illustrated in Fig. 2. Groundwater and infiltration loss are important in this kind of flooding.

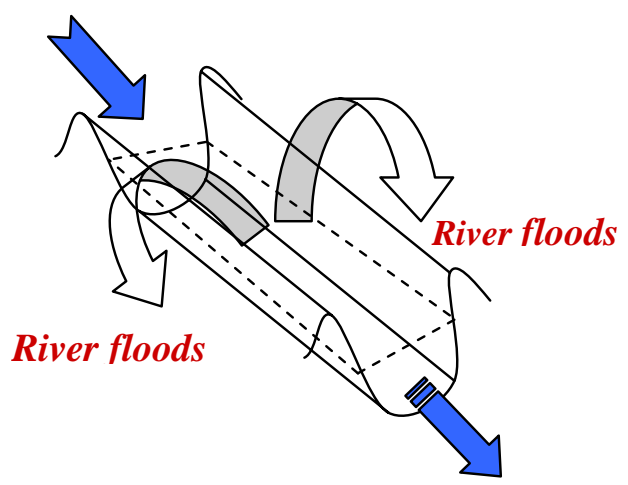

Flash floods 
Fig.2. Flash Floods and River Floods

\section{DEVELOPMENT OF THE ADJOINT FORMULATION}

A lot of numerical schemes (Nujic 1995; Jha et al. 1996; Jin and Fread 1997; Meselhe et al. 1997) have been developed to solve the open-channel flows with surges. However, most of these numerical models merely considered frictionless and horizontal channel flows. In this paper, a simple space and time staggered explicit finite difference scheme (M.B. Abbott et al 1989) had been developed to propagate and track the solution forward in time. The present model can calculate channel flows with bottom slope and friction terms in prismatic and which are important for main stream routing.. In addition, the method of characteristics with is incorporated in the schemes to deal with the open boundary conditions.

The method follows closely that described by (Sanders and Katopodes, 2000), and (Gejadze, I. Yu \& Copeland, G.J.M., 2005)

Take the Nonlinear Shallow Water Equations (SWEs)

$\frac{\partial H}{\partial t}+\frac{\partial q}{\partial x}=0 \quad \frac{\partial q}{\partial t}+g H\left(\frac{\partial H}{\partial x}+\frac{\partial z}{\partial x}\right)+K \frac{q|q|}{H^{2}}=0$

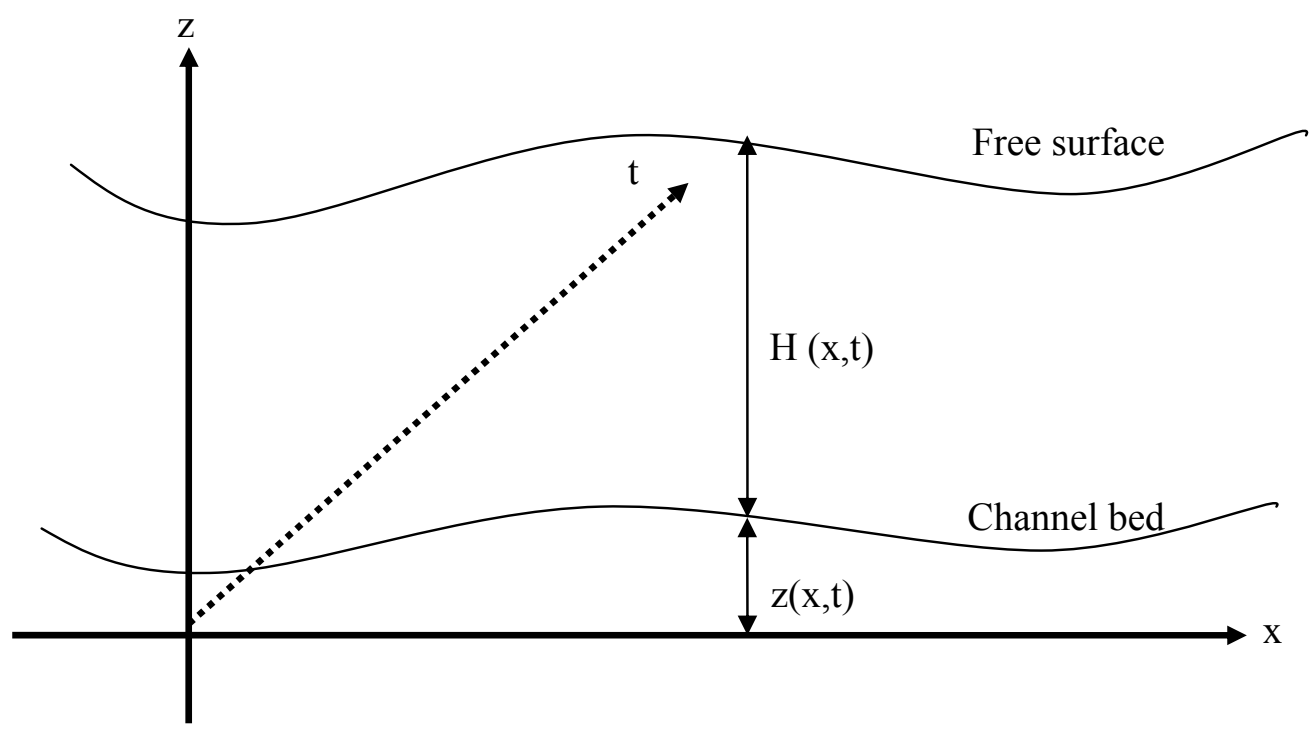


Fig.3. Flow in a channel with free surface under gravity.

Where:

$\mathrm{q}: \quad$ is the discharge per unit width $\left(\mathrm{m}^{2} \mathrm{~s}^{-1}\right)$.

$\mathrm{g}$ : is the gravitational acceleration.

$\mathrm{H}$ : $\quad$ is the total depth $(\mathrm{m})$ measured from the datum

$\mathrm{z}$ : $\quad$ vertical distance between the datum and the channel bed as function $(\mathrm{x}, \mathrm{t})$.

$\mathrm{t}: \quad$ is the time $(\mathrm{s})$.

$\mathrm{x}$ : $\quad$ is the horizontal distance along the channel (m).

$\mathrm{S}_{0}: \quad$ is the bed slope $=-\frac{\partial z}{\partial x}$.

$\mathrm{S}_{\mathrm{f}}: \quad$ is the bed friction term $=K \frac{q|q|}{H^{2}}\left(\mathrm{~m}^{2} \mathrm{~s}^{-2}\right)$.

$\mathrm{K}: \quad$ is a dimensionless friction factor $=\mathrm{g} / \mathrm{c}^{2}$ according to Chezy or $=\mathrm{gn}^{2} / \mathrm{H}^{(1 / 3)}$ according to Manning .

Define a quadratic measuring function that quantifies the water levels greater then some specified threshold flood level $\mathrm{H}_{\mathrm{d}}$.

$$
\mathrm{r}=0.5\left\{\left(\mathrm{H}-\mathrm{H}_{\mathrm{d}}\right)\left|\mathrm{H}-\mathrm{H}_{\mathrm{d}}\right|\right\} \delta\left(\mathrm{x}-\mathrm{x}_{\mathrm{o}}\right) \delta\left(\mathrm{t}-\mathrm{t}_{\mathrm{o}}\right)
$$

Where:

$\mathrm{H}(\mathrm{x}, \mathrm{t})$ is the solution of the forward model

$\mathrm{H}_{\mathrm{d}}\left(\mathrm{x}_{0}, \mathrm{t}_{\mathrm{o}}\right)$ is a data measurements at $\mathrm{x}=\mathrm{x}_{0}$

Construct the Lagrangian

$$
J=\int_{0}^{T} \int_{0}^{L}\left\{r+\phi\left[\frac{\partial H}{\partial t}+\frac{\partial q}{\partial x}\right]+\psi\left[\frac{\partial q}{\partial t}+g H\left(\frac{\partial H}{\partial x}+\frac{\partial z}{\partial x}\right)+K \frac{q|q|}{H^{2}}\right]\right\} d x d t
$$

Assuming constant bed slope, i.e. $\frac{\partial z}{\partial x}=$ constant

Take the first variation of the Lagrangian to identify the adjoint equations:- 


$$
\begin{aligned}
& \frac{\partial \phi}{\partial \tau}-g \frac{\partial H \psi}{\partial x}+\psi g \frac{\partial z}{\partial x}-2 K \psi \frac{q|q|}{H^{3}}+\frac{\partial r}{\partial H}=0 \\
& \frac{\partial \psi}{\partial \tau}-\frac{\partial \phi}{\partial x}+2 \psi K \frac{|q|}{H^{2}}+\frac{\partial r}{\partial q}=0
\end{aligned}
$$

Where $\tau=(\mathrm{T}-\mathrm{t})$ measured in reverse time direction.

\subsection{Initial and boundary conditions:}

Let the initial condition (at $\mathrm{t}=0$ ) remain unperturbed i.e. we do not want to adjust the initial conditions. So define initial conditions $\mathrm{H}(\mathrm{x}, 0)=\mathrm{H}_{0}(\mathrm{x}) ; \mathrm{q}(\mathrm{x}, 0)=\mathrm{q}_{0}(\mathrm{x})$ and set $\delta \mathrm{H}(\mathrm{x}, 0)=0$ and $\delta \mathrm{q}(\mathrm{x}, 0)=0$.

Also $\phi(\mathrm{x}, \mathrm{T})=0$ and $\psi(\mathrm{x}, \mathrm{T})=0$

i.e. there is no sensitivity information propagating in from outside the domain.

Therefore

$$
\delta J=\int_{0}^{T}[\phi \delta q+\psi g H \delta H]_{0}^{L} d t
$$

Because the residuals of the adjoint equations will be zero when a solution is found. From here on it depends on how the forward solution is defined. If ,say, we want to find the sensitivities of flood level to variations in $q(0, t)$ and $H(L, t)$, then we must set the sensitivities $\delta \mathrm{q}(\mathrm{L}, \mathrm{t})=0$ and $\delta \mathrm{H}(0, \mathrm{t})=0$ because these are not required.

This is done by setting

$$
\phi(\mathrm{L}, \mathrm{t})=0 \quad \text { and } \quad \psi(0, \mathrm{t})=0
$$

So now the sensitivities

$$
\frac{\delta J}{\delta q\left(0, t_{p}\right)}=-\phi\left(0, t_{p}\right) \quad \text { at each perturbation time } t_{p}
$$

and

$$
\frac{\delta J}{\delta H\left(L, t_{p}\right)}=\psi g H\left(L, t_{p}\right) \quad \text { at each perturbation time } t_{\mathrm{p}}
$$

But setting $\phi(\mathrm{L}, \mathrm{t})=0 \quad$ and $\quad \psi(0, \mathrm{t})=0 \quad$ [eq. 7] causes reflections which change the values of $\phi(0, \mathrm{t})$ and $\psi(\mathrm{L}, \mathrm{t})$ in ways that will invalidate them. The method of characteristics is used to identify boundary conditions that prevent reflections so allowing the correct values of sensitivities to be computed.

Flooding is created at the upstream boundary by defining a three hours hydrograph as presented in Fig.4. 


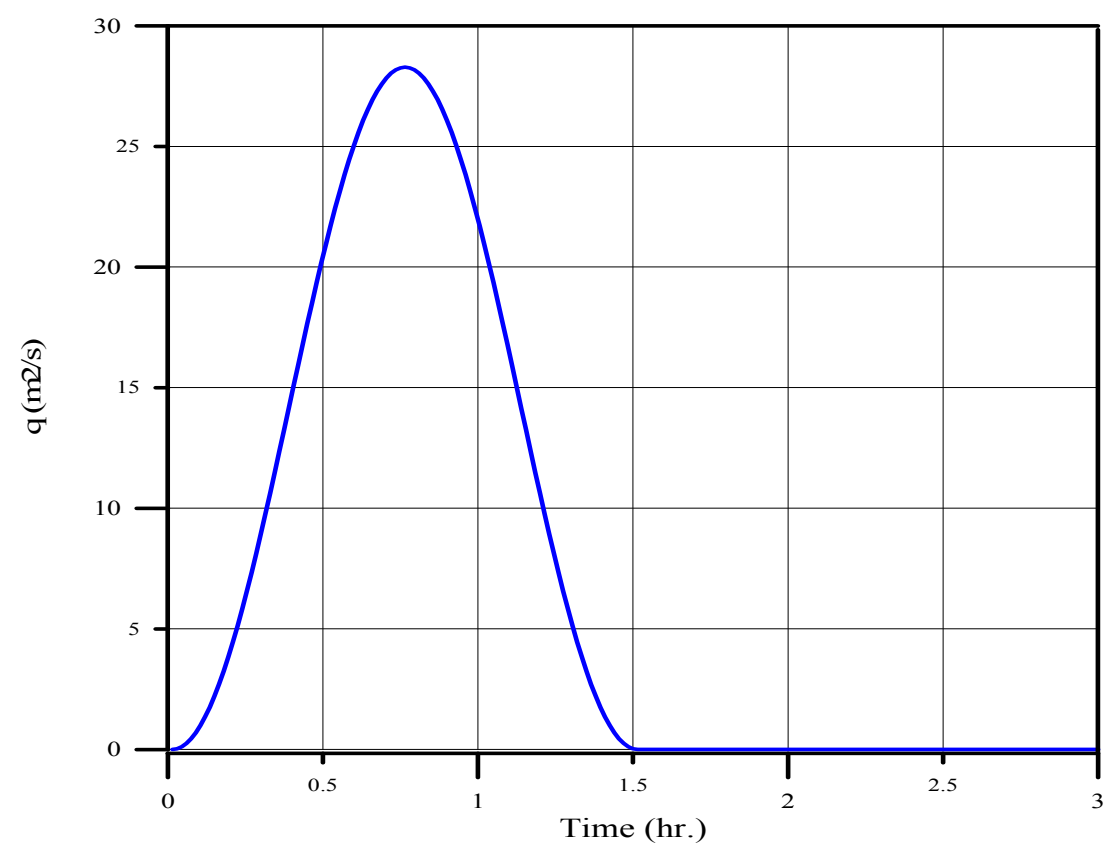

Fig.4. A three hours hydrograph at the upstream boundary

\subsection{Characteristics in the forward model:}

Following a standard text such as [French, 1986], the characteristics of the linearized SWEs are identified as:

$$
\begin{array}{lll}
\Delta q+c \Delta H+K \frac{q|q|}{H^{2}}-g H \frac{\partial \mathrm{z}}{\partial x}=0 & \text { [eq.10] } & \text { along } \mathrm{dx}=\mathrm{cdt} \text { (the positive characteristic) } \\
\Delta q-c \Delta H+K \frac{q|q|}{H^{2}}-g H \frac{\partial \mathrm{z}}{\partial x}=0 & \text { [eq.11] } & \text { along } \mathrm{dx}=-\mathrm{cdt}(\text { the negative characteristic) }
\end{array}
$$

Where $\Delta$ indicates a total change in variable along the characteristic path.

These are used in the discrete equations to find the boundary values $H(L, t)$ as follows :

From equation [11]

$$
\frac{\Delta q}{\Delta t}-c \frac{\Delta H}{\Delta t}=-K \frac{q|q|}{H^{2}}+g H \frac{\partial z}{\partial x}
$$

So

$$
c \frac{\Delta H}{\Delta t}=\frac{\Delta q}{\Delta t}-K \frac{q|q|}{H^{2}}+g H \frac{\partial z}{\partial x}
$$

Divide both sides by c

$$
\frac{\Delta H}{\Delta t}=\frac{1}{c}\left[\frac{\Delta q}{\Delta t}-K \frac{q|q|}{H^{2}}+g H \frac{\partial z}{\partial x}\right]
$$

Multiply both sides by $\Delta \mathrm{t}$

$$
\Delta H=\frac{\Delta q}{c}-\frac{\Delta t}{c}\left[K \frac{q|q|}{H^{2}}+g H \frac{\partial z}{\partial x}\right]
$$

From equation [12] we could get the boundary value of $\mathrm{H}$ at the boundary.

\subsection{Characteristics in the adjoint model:}

The same method is followed to identify the characteristics of the adjoint equations: along $\mathrm{dx}=\mathrm{c} d t$ (the positive characteristic)

$$
c \frac{\Delta \psi}{\Delta t}+\frac{\Delta \varphi}{\Delta t}+c\left[2 \psi \frac{S_{f}}{q}-\frac{\partial r}{\partial q}\right]-2 \psi \frac{S_{f}}{H}+\frac{\partial r}{\partial H}=0
$$


along $\mathrm{dx}=-\mathrm{c} \mathrm{dt}$ (the negative characteristic)

$c \frac{\Delta \psi}{\Delta t}-\frac{\Delta \varphi}{\Delta t}+c\left[2 \psi \frac{S_{f}}{q}-\frac{\partial r}{\partial q}\right]-2 \psi \frac{S_{f}}{H}+\frac{\partial r}{\partial H}=0$

These are used in the discrete equations to find the boundary values $\phi(L, t)$ and $\psi(0, t)$ by the same way to the derivation of equation [12] but in terms of adjoint variables instead of $\mathrm{H}$ and $\mathrm{q}$, results in :

$\Delta \varphi=-c \Delta \psi-2 c \psi \frac{S_{f}}{q}+2 \psi \frac{S_{f}}{H}$

From equation [15] we could get the value of $\Psi$ at the boundary and by the same way we could get the value of $\varphi$ as well.

\subsection{The Discrete Forward Model:}

The numerical scheme follows a simple space and time staggered explicit finite difference scheme. The discharge $\mathrm{q}$ is marched using the discrete form of the momentum equation:

$\mathrm{q}(\mathrm{i}, \mathrm{j}+1)=\mathrm{q}(\mathrm{i}, \mathrm{j})-(\Delta \mathrm{t} / \Delta \mathrm{x}) \mathrm{g} \mathrm{H}(\mathrm{i}, \mathrm{j})[\mathrm{H}(\mathrm{i}, \mathrm{j})-\mathrm{H}(\mathrm{i}-1, \mathrm{j})]-(\Delta \mathrm{t})\left[\mathrm{Kq}(\mathrm{i}, \mathrm{j})|\mathrm{q}(\mathrm{i}, \mathrm{j})| / \mathrm{H}(\mathrm{i}, \mathrm{j})^{2}\right] \quad$ [eq.16]

The elevation $\mathrm{H}$ is marched using the discrete form of the continuity equation:

$H(i, j+1)=H(i, j)-(\Delta t / \Delta x)[q(i+1, j+1)-q(i, j+1)]$

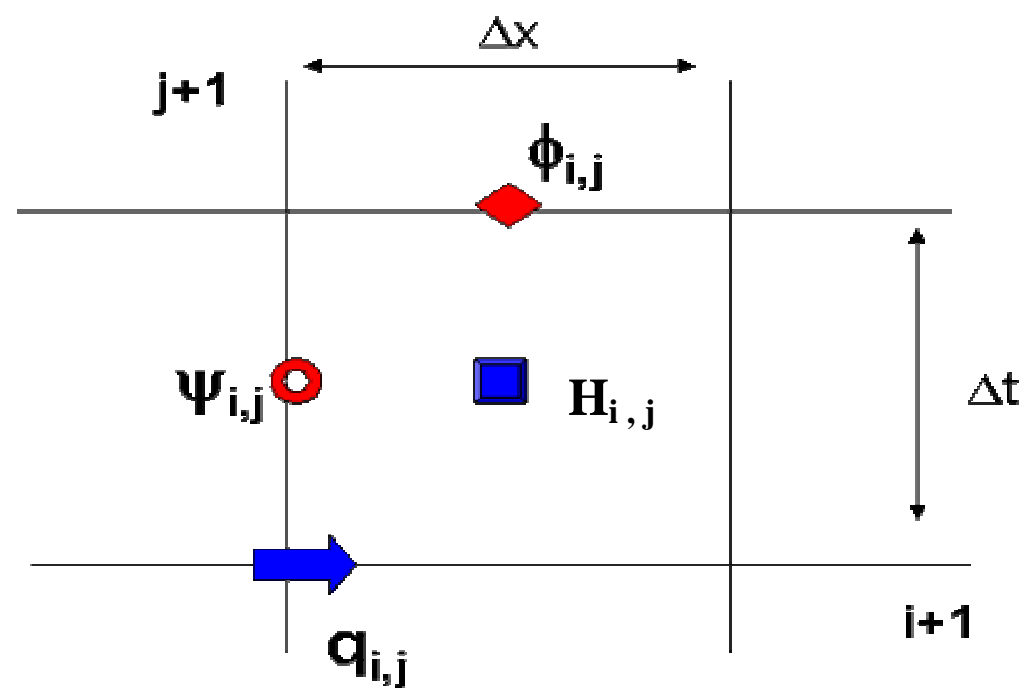

Fig.5. The discretization scheme

\subsection{The Discrete Adjoint Model:}

The numerical scheme also follows a simple space and time staggered, explicit finite difference scheme. The adjoint variable $\phi$ is marched backwards in time using the discrete form as follows.

$\phi(\mathrm{i}, \mathrm{j}-1)=\phi(\mathrm{i}, \mathrm{j})+(\Delta \mathrm{t} / \Delta \mathrm{x}) \mathrm{g}[\mathrm{H}(\mathrm{i}+1, \mathrm{j}) \psi(\mathrm{i}+1, \mathrm{j})-\mathrm{H}(\mathrm{i}, \mathrm{j}) \psi(\mathrm{i}, \mathrm{j})]-\Delta \mathrm{t}\left[\left(\eta-\eta_{\mathrm{o}}\right)+\right.$ $\left.\left|\eta-\eta_{\mathrm{o}}\right|\right]\left[\delta\left(\mathrm{i}-\mathrm{i}_{\mathrm{o}}\right) \delta\left(\mathrm{j}-\mathrm{j}_{\mathrm{o}}\right)\right]-2 \psi(\mathrm{i}, \mathrm{j}) \mathrm{Kq}(\mathrm{i}, \mathrm{j})|\mathrm{q}(\mathrm{i}, \mathrm{j})| / \mathrm{H}(\mathrm{i}, \mathrm{j})^{3}$ 
The adjoint variable $\psi$ is marched using the discrete form as follows:

$\psi(\mathrm{i}, \mathrm{j}-1)=\psi(\mathrm{i}, \mathrm{j})+(\Delta \mathrm{t} / \Delta \mathrm{x})[\phi(\mathrm{i}, \mathrm{j}-1)-\phi(\mathrm{i}-1, \mathrm{j}-1)]+2 \psi(\mathrm{i}, \mathrm{j}) \mathrm{K}|\mathrm{q}(\mathrm{i}, \mathrm{j})| / \mathrm{H}(\mathrm{i}, \mathrm{j})^{2}$

\section{STABILITY OF THE SCHEME:}

it is essential that the finite difference scheme used should be fully tested for stability before proceeding with developing the numerical model. To investigate the analytically the stability of the simple space and time staggered, explicit finite difference scheme to present the shallow water equations $[1,2]$ the Fourier method had been applied and as a result this scheme will be stable if and only if $C F L \leq 1.0$

Where:

$C F L=\frac{\Delta t}{\Delta x} \sqrt{g h}$ is the Courant-Friedrich-Lewy number

So a value of $C F L=0.5$ was used in the test case described below:

\section{TEST CASES}

\subsection{Case (1):}

\subsubsection{Description:}

A horizontal channel with a driving upstream hydrograph (producing wave of initial amplitude $a=2.0 \mathrm{~m}$ ) in uniform water depth without bed friction and with closed boundaries.

A hydrograph was defined that produce a wave of initial amplitude a $=2.0 \mathrm{~m}$ with maximum discharge of $28.28 \mathrm{~m}^{2} / \mathrm{s}$ in a water depth of $\mathrm{d}=20 \mathrm{~m}$. The grid was $\mathrm{nt}=400$ time steps and $\mathrm{nx}$ $=50$ space steps That result in a domain size of length $\mathrm{L}=76.3675 \mathrm{Km}$ and time $\mathrm{T}=6.0$ hours, and, this gave values $\mathrm{dx}=1527.35 \mathrm{~m}$ and $\mathrm{dt}=54$ seconds. the upstream driving boundary is a three hours hydrograph of $28.28 \mathrm{~m}^{2} / \mathrm{s}$ maximum discharge Fig. 4 that satisfies $\mathrm{q}=\mathrm{a} \sqrt{ }(\mathrm{g} \mathrm{d})(1+\sin$ theta), $\mathrm{a}=2.0 \mathrm{~m}$. The wave speed $\mathrm{c}=\sqrt{ }(\mathrm{g} \mathrm{d})$ everywhere. The initial condition was $\mathrm{H}(\mathrm{x}, 0)=20 \mathrm{~m}$ and $\mathrm{q}(\mathrm{x}, 0)=0$. The data was defined as the safe water level at $\mathrm{x}$ $=\mathrm{x} 0$ to be $0.2 \mathrm{a}(\mathrm{m})$. The data is shown in Fig. (6-B).

\subsubsection{Results and Result Analysis for case (1):}

The hydrograph traveled from the upstream boundary to the downstream boundary with no decrease in the maximum discharge, Fig. (6-D), but as expected reflections occurred at the boundaries, see Fig. (6-A), and Fig. (6-D). Of course, this does not match the real world case we study. The small oscillations on the results for $\phi$ and $\psi$, see Fig. (6-E), and Fig. (6-F), are caused by the shock source term at $t=6.0$ hours as in Fig (6-C) which propagate backward in time through the adjoint model with reflections from $\mathrm{x}=0$ to $\mathrm{x}=\mathrm{L}$. The sensitivities of the flood level being greater than the "safe water level" in terms to upstream discharge and downstream water level are shown in Fig. (6-H), and Fig. (6-G) respectively. Note that these are dominated by the shock and its reflections. 


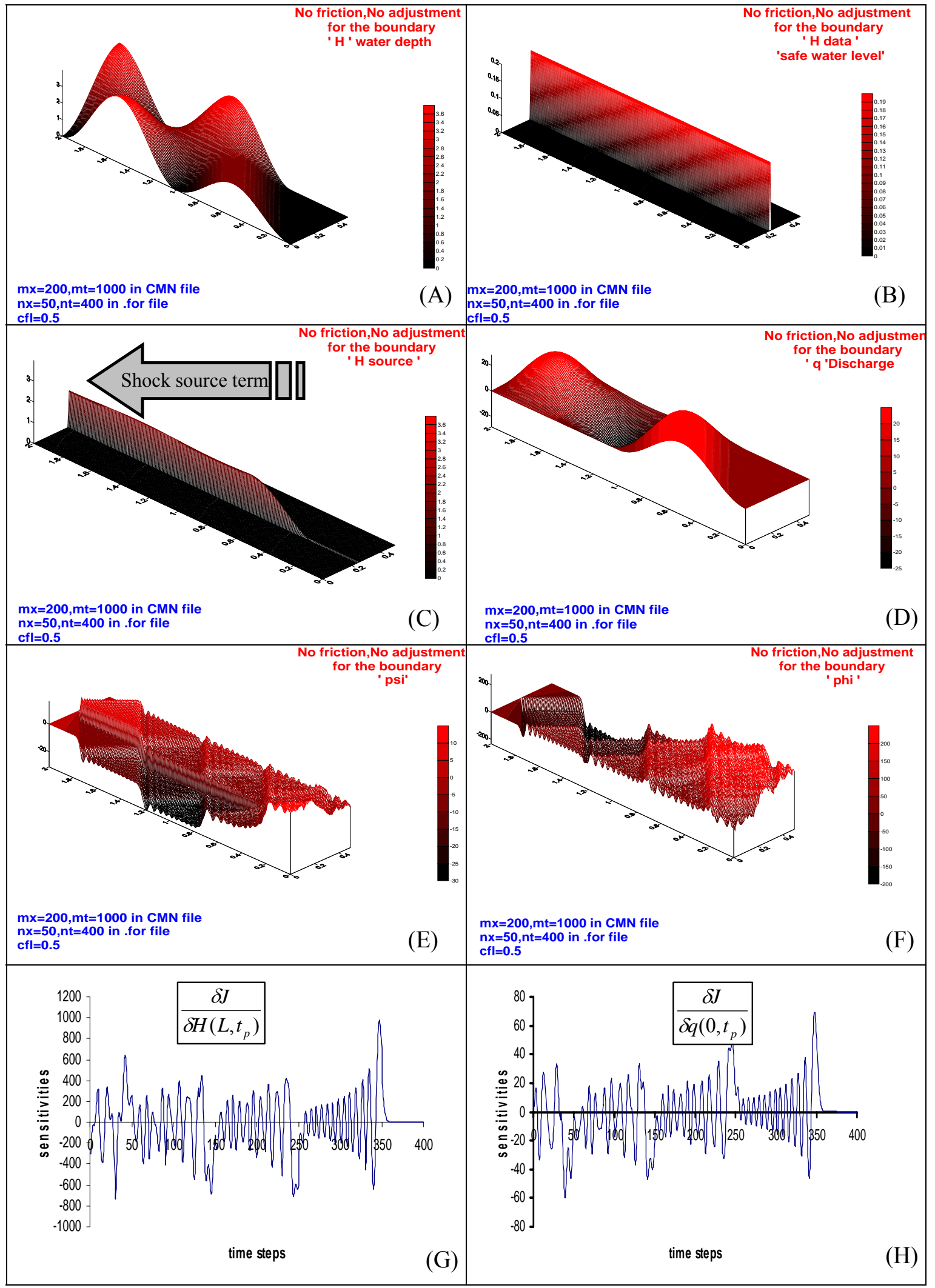

Fig.6. Case (1) 


\subsection{Case (2):}

\subsubsection{Description:}

\section{A horizontal channel with a driving upstream hydrograph (producing wave of initial amplitude $a=2.0 \mathrm{~m}$ ) in uniform water depth without bed friction but with open boundaries}

It is the same physical behavior as case (1) but with time domain half that of case (1) i.e. nt = 200 time steps and the same $\mathrm{nx}=50$ space steps. Here the method of characteristics had been used to produce open, non reflective boundaries in both the forward, Fig. (7-A, D), and adjoint models, Fig. (7-E, F), by applying the following equations for the forward model:

$$
\begin{aligned}
& \Delta q+c \Delta H=0 \\
& \Delta q-c \Delta H=0
\end{aligned}
$$

And the following equations for the adjoint model:

$$
\begin{aligned}
& c \frac{\Delta \psi}{\Delta t}+\frac{\Delta \varphi}{\Delta t}-c\left[\frac{\partial r}{\partial q}\right]+\frac{\partial r}{\partial H}=0 \\
& c \frac{\Delta \psi}{\Delta t}-\frac{\Delta \varphi}{\Delta t}+c\left[\frac{\partial r}{\partial q}\right]+\frac{\partial r}{\partial H}=0
\end{aligned}
$$

Thus, this case omits the friction term i.e. not including the bed friction coefficient $\mathrm{K}$ compared to equations $[10,11,13$, and 14$]$

The data is shown in Fig.7

\subsubsection{Results and Result Analysis for case (2):}

The hydrograph traveled from the upstream boundary to the downstream boundary with a constant maximum discharge of $28.28 \mathrm{~m}^{2} / \mathrm{s}$, see Fig.(7-D). The sensitivities $\frac{\delta J}{\delta q(1, j)}=-\phi(0, j)$ and $\frac{\delta J}{\delta H\left(L, t_{p}\right)}=\psi g H\left(L, t_{p}\right)$ are shown in Fig. (7-H, G) by the profiles of $\varphi$ at $\mathrm{x}=0$ and $\Psi$ at $\mathrm{x}=\mathrm{L}$ respectively, these show the expected form being defined by the source terms which has a similar profile to the data. The clear development along characteristics is also apparent. These are the same characteristics as in the forward model. The efficiency of the method to define boundary values is clear because of the absence of reflections from the boundaries $\mathrm{x}=0$ and $\mathrm{x}=\mathrm{L}$. We note that, because there is no reflection in the forward model at $\mathrm{x}=\mathrm{L}$, the source term Fig. (7-C), no longer has a shock at $\mathrm{t}=\mathrm{T}$, the results for $\Psi$ and $\varphi$ are now smooth and correctly follow the response to the hydrograph. 


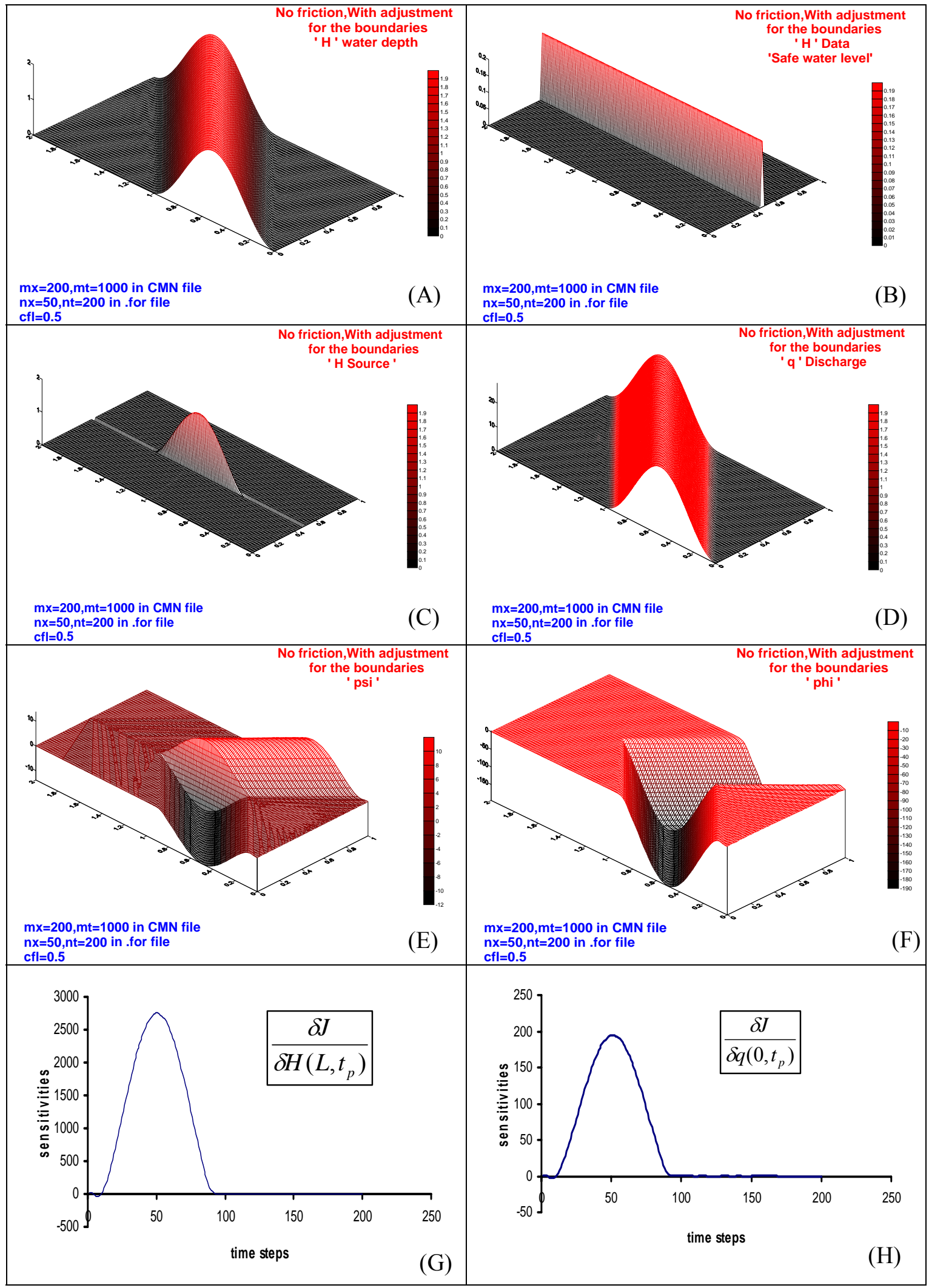

Fig.7. Case (2) 


\subsection{Case (3)}

\subsubsection{Description:}

A horizontal channel with a driving upstream hydrograph (producing wave of initial amplitude $a=2.0 \mathrm{~m}$ ) in uniform water depth with bed friction and with open boundaries.

It is same as case (2) except we added a friction term which is $K \frac{q|q|}{H^{2}}$ to the momentum equation. The absence of reflections in both the forward and adjoint models had been shown in Fig. (8-A, D), and in Fig. (8-E,F) by applying the following equations for the forward model:

$$
\begin{aligned}
& \Delta q+c \Delta H+K \frac{q|q|}{H^{2}}=0 \\
& \Delta q-c \Delta H+K \frac{q|q|}{H^{2}}=0
\end{aligned}
$$

And the following equations for the adjoint model:

$$
\begin{aligned}
& c \frac{\Delta \psi}{\Delta t}+\frac{\Delta \varphi}{\Delta t}+c\left[2 \psi \frac{S_{f}}{q}-\frac{\partial r}{\partial q}\right]-2 \psi \frac{S_{f}}{H}+\frac{\partial r}{\partial H}=0 \\
& c \frac{\Delta \psi}{\Delta t}-\frac{\Delta \varphi}{\Delta t}+c\left[2 \psi \frac{S_{f}}{q}-\frac{\partial r}{\partial q}\right]-2 \psi \frac{S_{f}}{H}+\frac{\partial r}{\partial H}=0
\end{aligned}
$$

These equations had been applied for the adjustment of the boundaries based on the method of characteristics and were correctly implemented including the friction terms.

\subsubsection{Results and Result Analysis for case (3):}

The hydrograph traveled from the upstream boundary to the downstream boundary with a decreasing in the maximum discharge from $28.28 \mathrm{~m}^{2} / \mathrm{s}$ to $17.66 \mathrm{~m}^{2} / \mathrm{s}$, see Fig.(8-C).

The sensitivities $\frac{\delta J}{\delta q(1, j)}=-\phi(0, j)$ and $\frac{\delta J}{\delta H\left(L, t_{p}\right)}=\psi g H\left(L, t_{p}\right)$ are shown in Fig. $(8-\mathrm{H}, \mathrm{G})$

by the profiles of $\varphi$ at $\mathrm{x}=0$ and $\Psi$ at $\mathrm{x}=\mathrm{L}$ respectively These show the expected form being defined by the source terms which has a similar profile to the data and the clear development along characteristics is also apparent. However the nonlinear effects of the friction term produce a significant distortion of the hydrograph shape as illustrated in (Fig.8-E, F, G, and $\mathrm{H})$.

The peak discharge reduces along the channel (Fig. 8-D), so the balance of water is expressed as channel storage (Fig. 8-A). The corresponding reduction in sensitivities of flood levels at $\mathrm{x}_{0}$ to the inflow hydrograph is quantified by comparing the peak values of $\frac{\delta J}{\delta q(1, j)}=-\phi(0, j)$ .These reduce from a value of 200, Fig. (7-H) to a value of 110 . Fig. (8-H). In other words, as storage upstream of $\mathrm{x}_{0}$ increases so the sensitivity to the inflow hydrograph decreases. 


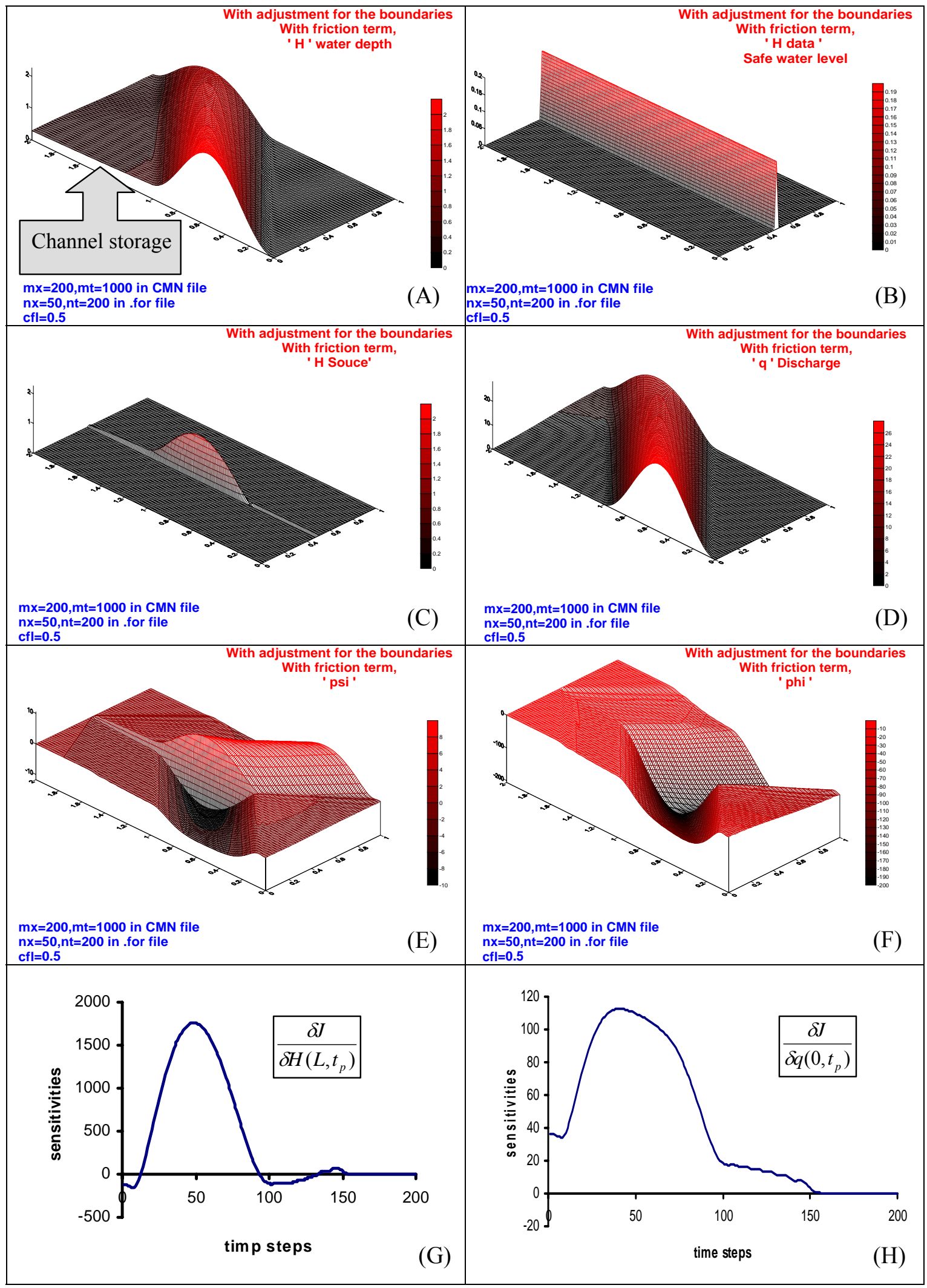

Fig.8. Case (3) 


\section{CONCLUSIONS}

This paper demonstrates that the sensitivities of flood level excess can be calculated directly using the adjoint method in a single model run. This is more efficient than sensitivity estimation using multiple runs.

This approach can be used as a stepping stone to uncertainty analysis since it identifies the parameters that should be considered in both combined sensitivity analysis (i.e. looking at effects of uncertainties in combinations of parameters) and in uncertainty analysis involving stochastic methods like Monte Carlo Simulation .

These preliminary results already show the strong effect that the friction has in changing sensitivities and demonstrate the role of channel storage in reducing sensitivities.

\section{FUTURE WORKS}

The paper presents the first step in a study of sensitivities for flash floods forecast in rapid response catchment. The work will be extended to include the infiltration loss rate and bed slope as well and after that the adjoint sensitivities will be used to guide a stochastic uncertainty analysis.

\section{ACKNOWLEDGMENTS}

The author would like to express his deepest gratitude to prof. Dr. Osama M.Moussa for his sincere concern and useful guidance through and before my $\mathrm{PhD}$ research.

I am particularly appreciating my sponsor at my country who gave me this chance to complete my study.

Last but not least, I would like to thank all my colleagues and the staff of civil engineering department of Strathclyde University. 


\section{REFERNCES}

\begin{tabular}{|c|c|}
\hline 1 & $\begin{array}{l}\text { Cheng, R. T., Casulli, V., and Gartner, J. W. (1993). "Tidal, residual, } \\
\text { intertidal mudflat (TRIM) model and its application to San Francisco Bay, } \\
\text { California."' Estuarine, Coast. and Shelf Sci., 36, 235-280. }\end{array}$ \\
\hline 2 & $\begin{array}{l}\text { Copeland, G.J.M. (1998), Coastal Flow modeling using an inverse method } \\
\text { with direct minimization, Proc. Conf. Estuarine and Coastal Modeling, } 1997 . \\
\text { Ed. M.L.Spaulding \& A.F. Blumberg, Pub. ASCE (ISBN 0-7844-0350-3) } \\
\text { pp.279-292. }\end{array}$ \\
\hline 3 & $\begin{array}{l}\text { D.G.Cacuci (2003), “Sensitivity and Uncertainty } \\
\text { Volume I",Chapman \& Hall CRC. }\end{array}$ \\
\hline 4 & French, R.H. (1986), Open Channel Hydraulics, McGraw Hill \\
\hline 5 & $\begin{array}{l}\text { Gejadze, I. Yu \& Copeland, G.J.M., (2005) 'Open Boundary Control for } \\
\text { Navier-Stokes Equations Including the free Surface: Adjoint Sensitivity } \\
\text { Analysis', Computers \& Mathematics with Applications, Elsevier.(accepted } \\
\text { for publication) }\end{array}$ \\
\hline 6 & $\begin{array}{l}\text { Jha, A. K., Akiyama, J., and Ura, M. (1996). “A fully conservative Beam } \\
\text { and Warming scheme for transient open channel flows.” J. Hydr. Res., } \\
\text { Delft, The Netherlands, 34(5), 605-621. }\end{array}$ \\
\hline 7 & $\begin{array}{l}\text { Jin, M., and Fread, D. L. (1997). "Dynamic flood routing with explicit } \\
\text { and implicit numerical solution schemes.' J. Hydr. Engrg., ASCE, } \\
\text { 123(3), 166-173. }\end{array}$ \\
\hline 8 & $\begin{array}{l}\text { M.B. Abbott and D.R. Basco, Computational Fluid Dynamics: An } \\
\text { Introduction for Engineers, Longman Scientific \& Technical, Essex, UK, } \\
\text { 1989. }\end{array}$ \\
\hline 9 & $\begin{array}{l}\text { M.B. Abbott, An Introduction to the method of characteristics, Thames and } \\
\text { Hudson,London UK, } 1977 \text {. }\end{array}$ \\
\hline 10 & $\begin{array}{l}\text { Meselhe, E. A., Sotiropoulos, F., and Holly, F. M., Jr. (1997). "Numerical } \\
\text { simulation of transcritical flow in open channels." J. Hydr. Engrg., } \\
\text { ASCE, 123(9), 774-783. }\end{array}$ \\
\hline 11 & $\begin{array}{l}\text { Nujic, M. (1995). “Efficient implementation of non-oscillatory schemes } \\
\text { for the computation of free-surface flows.” J. Hydr. Res., Delft, The } \\
\text { Netherlands, 33(1), 101-111. }\end{array}$ \\
\hline 12 & $\begin{array}{l}\text { Sanders, B.F and Katopodes, N.D. (2000) Adjoint Sensitivity analysis for } \\
\text { shallow-water wave control. J. Eng. Mech., ASCE, pp 909-919 }\end{array}$ \\
\hline 13 & $\begin{array}{l}\text { Steinebach, G. (1998). “Using hydrodynamic models in forecast systems for } \\
\text { large rivers." Advances in hydroscience and engineering, K. P. Holz, W. } \\
\text { Bechteler, S. S. Y. Wang, and M. Kawahara, eds., Vol. } 3 \text {. }\end{array}$ \\
\hline 14 & $\begin{array}{l}\text { U.S. Army Corps of Engineer, (1988), "HEC-1, flood hydrology Package" } \\
\text { (1988 version): Hydrologic Engineering Center, Davis, California. }\end{array}$ \\
\hline
\end{tabular}

